Article

\title{
Experimental and Numerical Study on Mechanical Analysis of Buried Corroded Concrete Pipes under Static Traffic Loads
}

\author{
Hongyuan Fang $1,2,3,4$, Kangjian Yang ${ }^{1,2,3, *}$, Bin Li ${ }^{1,2,3}$, Peiling Tan ${ }^{1,2,3}$, Fu Wang ${ }^{1,2,3}$ and \\ Xueming Du ${ }^{1,2,3, *}$ \\ 1 School of Water Conservancy Engineering, Zhengzhou University, Zhengzhou 450001, China; \\ 18337192244@163.com (H.F.); 13523519067@163.com (B.L.); tpl1752311002@163.com (P.T.); \\ 13938585462@163.com (F.W.) \\ 2 National Local Joint Engineering Laboratory of Major Infrastructure Testing and Rehabilitation Technology, \\ Zhengzhou 450001, China \\ 3 Collaborative Innovation Center of Water Conservancy and Transportation Infrastructure Safety, \\ Zhengzhou 450001, China \\ 4 Southern Engineering Inspection and Restoration Technology Research Institute, Huizhou 516029, China \\ * Correspondence: yangkangjian@gs.zzu.edu.cn (K.Y.); dxm2019@zzu.edu.cn (X.D.); \\ Tel.: +86-132-5367-1350 (K.Y.)
}

Received: 23 October 2019; Accepted: 16 November 2019; Published: 20 November 2019

Featured Application: This study reveals the mechanical properties of corroded pipes under traffic loads and can be applied to the evaluation of corroded pipes.

\begin{abstract}
Concrete pipes are widely used in municipal drainage projects. Corrosion is a common issue affecting concrete pipes, causing leakage of pipes, environmental pollution, and road collapse. It is necessary to study the mechanical properties of corroded concrete pipes. To investigate in depth the influence of corrosion depths, corrosion widths, traffic loads, and cover depths, on mechanical characteristics of buried corroded concrete pipes under static traffic loads, a series of full-scale tests were carried out. Then, a three-dimensional finite element model of buried corroded concrete pipes under traffic loads is established based on ABAQUS. Results showed that the inside of the pipe wall is more vulnerable to damage than the outside. The stress and strain of a corroded pipe is significantly larger than that of an uncorroded pipeline. The corrosion has a great influence on the stress and strain of the corroded area. The maximum principal stress and circumferential strain at corroded area increase with increasing of corrosion depth. The stress and strain first increases rapidly $\left(0-10^{\circ}\right)$, and then decreases rapidly $\left(10-45^{\circ}\right)$, then finally decreases slowly $\left(45-180^{\circ}\right)$ with an increase of corrosion width. In addition, the greater cover depth or increasing traffic load causes a rapid increase in both circumferential strain and the maximum principal stress.
\end{abstract}

Keywords: concrete pipe; corrosion; mechanical characteristics; traffic loads

\section{Introduction}

The total length of urban drainage pipelines in China has exceeded $57.7 \mathrm{~km}$, according to the Ministry of Housing and Urban-Rural Development of PRC [1,2]. Drainage pipelines built before 2000 account for $44.97 \%$ of the total length. The government is concerned by the frequent occurrence of accidents, such as road collapse and environmental pollution, due to the long-term neglect of pipeline repairs. Pipe wall corrosion due to the long-term effects of loads from road traffic causes accidents; it is 
one of the most common failures of buried concrete drainage pipelines [3,4]. There is an urgent need to identify the mechanical action of traffic loads on buried corroded concrete pipes.

Current research on the mechanical response of pipelines to surface traffic loading is mainly concerned with normal pipelines. Wang et al. [5] developed a 3D numerical model of a drainage pipe with gasketed bell-and-spigot joints using ABAQUS finite element software. They analyzed the dynamic response of drainage pipes to different impulses, load positions, and pipe depths. Lay et al. [6] conducted a full-scale physical experiment to study the mechanical response of buried reinforced concrete pipes to different axle loads at various pipe depths. Meesawasd et al. [7] investigated the effects of pipe depth, seismic events, car weight and speed, and traffic patterns on the stress distribution of a buried pipeline using the finite element method. Rakitin et al. [8] investigated the vertical displacement and joint rotation of reinforced concrete pipes with gasketed bell-and-spigot joints through a series of centrifuge tests. Xu et al. [9] examined the influence of traffic load distribution, gasket stiffness, and soil stiffness on the longitudinal behavior of the pipeline and the directional effects of traffic loads on the rotation and shear displacement of pipeline joints. Dong et al. [10] analyzed the effects of rock fall in terms of impact height, buried depth, pipe diameter, and pipe wall thickness on strain in the pipeline through experimentation and the use of a numerical model. Jasmin et al. [11] conducted a full-scale experiment to determine the joint behavior of concrete pipes under various loading conditions. Fang et al. [12] investigated the mechanics of a drainage pipeline under a traffic load before and after polymer grouting and cement grouting in trenchless pipe repair. They examined the mechanical effects of load type, load location, and pipe depth on the pipe.

Research into corrosion of concrete pipes focuses on the failure and reliability analysis of corroded concrete pipes. Renato et al. [13] examined failure pressure of corroded pipelines using nonlinear FE analysis, and the results was validated by experimental burst tests and semi-empirical method. $\mathrm{Xu}$ et al. [14] investigated the failure behavior of pipelines with interacting corrosion using a finite element method and proposed a solution to predict burst pressure using an artificial neural network. Han et al. [15] investigated the mechanical behavior and failure pressure of a pipe with a single internal corrosion damage location, multiple interacting internal corrosion damage locations, and multilayered structural internal corrosion damage locations using nonlinear finite element analysis. Ye et al. [16] investigated the effects of tension on collapse pressure by creating a finite element model of a pipeline with uniform symmetric axial corrosion. They conducted an extensive parametric investigation of the effects of loading path, initial damage length, yielding anisotropy and corrosion damage length on the collapse behavior under combined loads. Zhou et al. [17] developed a methodology to evaluate the annual failure probabilities of a pressurized pipeline with corrosion defects and determined the sensitivity of the calculated failure probabilities with respect to the time dependency of the internal pressure. Seyedeh et al. [18] investigated the time-dependent performance of pipelines subjected to external corrosion using reliability analysis and proposed a power-law function of time model to probabilistically predict the growth of corrosion maximum defect depth and defect length. Ahammed et al. [19] calculated the relative contribution of the random variables and the sensitivity of the reliability index of the nonlinear corrosion model to conduct the probabilistic analysis of underground pipelines subject to combined stresses and corrosion.

Although the above studies have done a lot of research on the mechanical properties of concrete pipes and the failure of corroded pipes, there has been limited research on the mechanics of the response of buried corroded concrete pipes under traffic loads. In this study, a three-dimensional finite element model and a full-scale experiment of buried corroded concrete pipes under traffic loads (the fatigue phenomena due to repeated load is neglected) were conducted to investigate the mechanical properties of buried corroded concrete drainage pipes. The effects of the depth of corrosion (corrosion depth) and the width of corrosion (corrosion width) in the pipe wall, traffic load, and cover depth, on the distribution of stress and strain in the pipe were analyzed. The results of this study provide a strong theoretical basis for evaluating the performance of buried corroded concrete drainage pipes. 


\section{Full-Scale Experiment}

A full-scale experiment was conducted to investigate the mechanical properties of corroded pipes under traffic loads. The process of the test was constructed in accordance with the code for construction and acceptance of water and sewerage pipeline works [20]. The bottom width, top width, height, and length of the excavation were 3.0, 4.5, 2.3, and $10.0 \mathrm{~m}$, respectively. An inspection chamber was installed at each end of the excavation. The length, width, and height of the inspection chambers were 2.5, 2.5, and $3.0 \mathrm{~m}$, respectively. Experimental setup for full-scale test is shown in Figure 1.

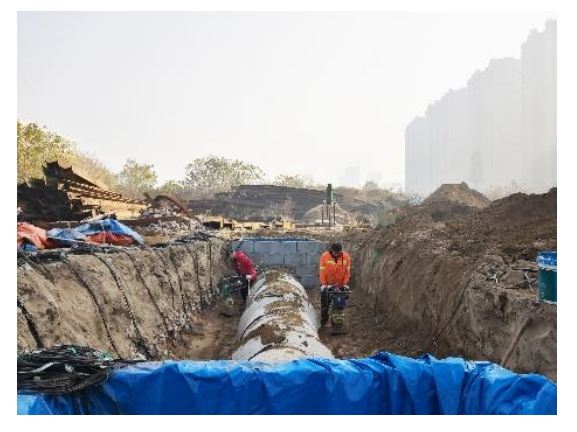

Figure 1. Experimental setup for full-scale test.

\subsection{Material Characteristics}

\subsubsection{Soil Characteristics}

Foundation pits were backfilled with undisturbed soil and medium-coarse sand. The sand bedding, which was laid and compacted using medium-coarse sand with particle size $<25 \mathrm{~mm}$, was laid around the bottom of the pipe at a level of $120^{\circ}$ subtended below the springline. Bed compaction was $92 \% \pm 3 \%$, and depth was $0.15 \mathrm{~m}$. The rest of the foundation pit was backfilled with undisturbed soil. A line of soil $0.5 \mathrm{~m}$ above the top of the pipe was used as a separator; fill was compacted once every $15 \mathrm{~cm}$ below the line and once every $30 \mathrm{~cm}$ above it. The cross-section of pipe bedding is shown in Figure 2 . The material parameters are shown in Table 1.

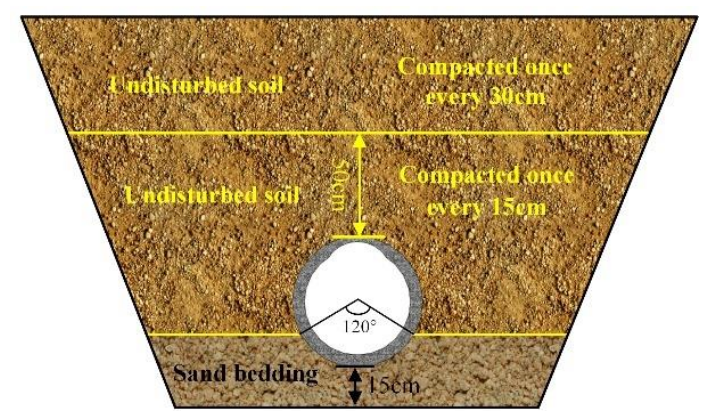

Figure 2. Cross-section of pipe bedding.

Table 1. Material parameters.

\begin{tabular}{cccccc}
\hline Material & $\rho\left(\mathbf{k g} / \mathbf{m}^{3}\right)$ & $E \mathbf{~ M P a})$ & $\boldsymbol{v}$ & $c(\mathbf{K P a})$ & $\psi\left({ }^{\circ}\right)$ \\
\hline Soil & 1732 & 28.9 & 0.3 & 17.3 & 25.2 \\
Sand bedding & 1921 & 57.5 & 0.2 & 4.7 & 41.3 \\
Pipeline & 2300 & 30,000 & 0.2 & - & - \\
\hline
\end{tabular}

\subsubsection{Pipeline Characteristics}

The pipeline consisted of four pipe sections with an inside diameter of $1.0 \mathrm{~m}$, wall thickness of $0.1 \mathrm{~m}$, and effective length of $2.5 \mathrm{~m}$. The detailed geometry of the pipe joints was consistent with the 
Chinese code for concrete and reinforced concrete sewer pipes [21]. Corrosion defects of the pipe were located at the crown of pipe, and corrosion depth was $0.03 \mathrm{~m}$, corrosion width was $60^{\circ}$.

There are two ways to synthetically corrode a pipe. One is to use a corrosive chemical, such as sulfuric acid, to simulate long-term corrosion; the other is to use a cutter and a sander. There are many disadvantages of using chemical reagents, such as high risk, a long test period, high waste disposal costs, and the corrosion is not easily quantifiable. Therefore, we used a sander to simulate pipe corrosion (Figure 3).

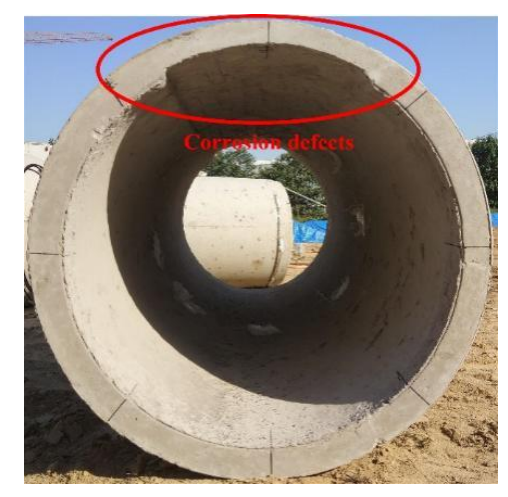

Figure 3. Simulated pipe corrosion.

\subsection{Test Equipment}

\subsubsection{Data Acquisition Equipment}

The data acquisition system had three components: a resistive strain gauge, a DH3816N static strain testing system, and a computer (Figure 4). DH3816N has 64 channels and it can accurately test the physical quantities such as strain, stress, displacement, and velocity. The product model of strain gauge is BQ-80AA-P120, the resistance is $120 \pm 0.2 \Omega$ and sensitivity coefficient is $2.2 \% \pm 1 \%$.

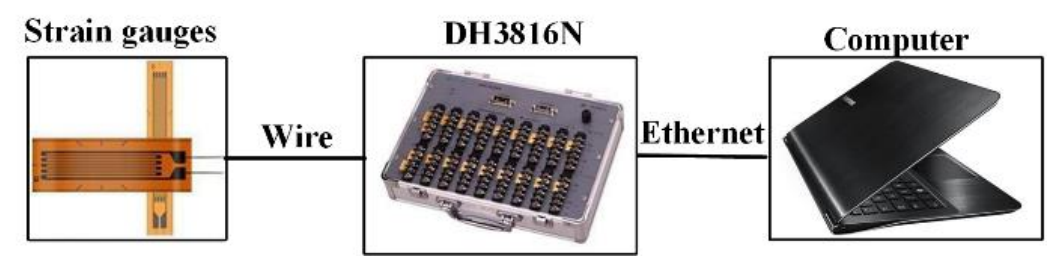

Figure 4. Data acquisition system.

\subsubsection{Vehicle Load}

The vehicle load for this test was supplied by a heavy truck carrying standard blocks (Figure 5). The front and the rear axle load of the truck were 4.47 and 8.93 tons. Twelve standard blocks, each weighing 1 ton, were loaded onto the truck, giving a total vehicle weight of 25.4 tons. The rear track, wheelbase, and tire grounding dimensions of the truck were $2.4 \mathrm{~m}, 5.5 \mathrm{~m}$, and $0.21 \mathrm{~m} \times 0.21 \mathrm{~m}$. The ground pressure of each wheel can be calculated using Equation (1).

$$
P=S / F
$$

where $P$ is the ground pressure, $F$ is the load generated by the vehicle wheel, and $S$ is the area of wheel contact with the ground. 


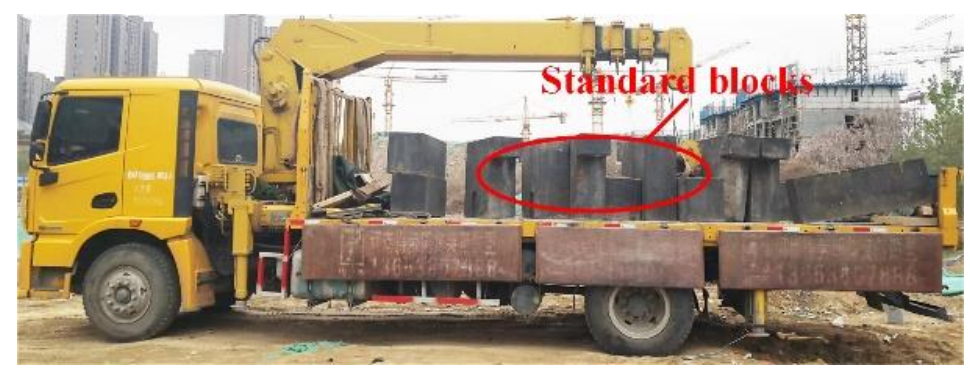

Figure 5. Full-scale traffic load.

\subsection{Test Program}

In this test, the cover depth of the pipeline was set to $1.0 \mathrm{~m}$. The traffic load, which was about 1.0 MPa calculating by Equation (1), was applied to the pipe joints of P2 and P3. The corrosion depth and corrosion width of the corroded pipe were $0.03 \mathrm{~m}$ and $60^{\circ}$.

Wang et al. [5] observed that the joint between pipes is a potential location of damage. Thus, the mechanical properties of the pipe joint were examined in this test. The strain gauges were arranged in an eight-point star pattern on both the outside and inside of the walls of the P2 bell, P3 spigot, as shown in Figure 6. The data sampling frequency of this test was $2.0 \mathrm{~Hz}$, and zero drift was $<1$ $\mu \varepsilon / 24 \mathrm{~h}$.

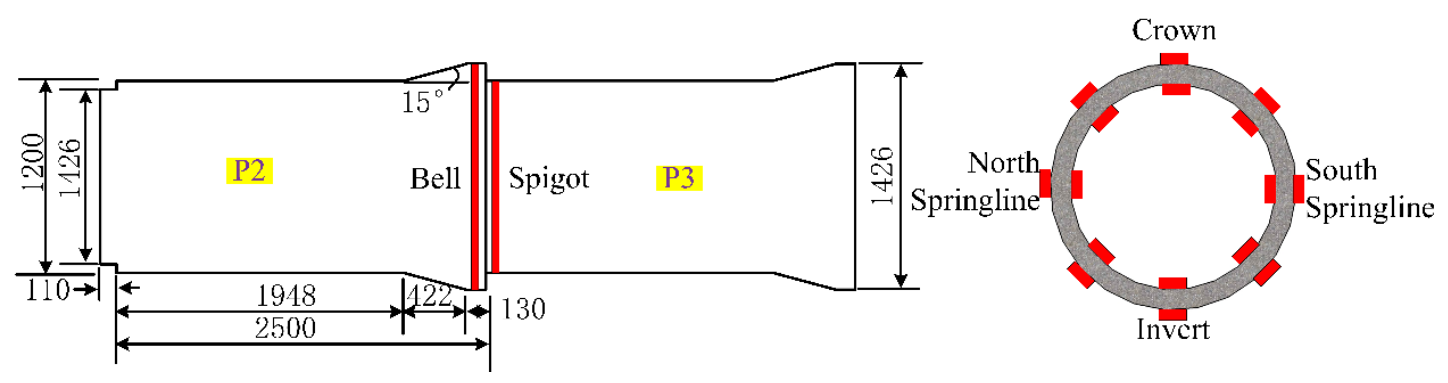

Figure 6. Strain gauge configuration.

\section{D Numerical Model of Buried Corroded Concrete Pipelines}

\subsection{The Mechanism of Pipeline Corrosion}

Erickson [22] found that corrosion within buried concrete pipelines is caused mainly by hydrogen sulfide gas in the pipeline. The process is: Sulfate ions in the sewage inside the pipeline are reduced to hydrogen sulfide by the action of anaerobic bacteria; hydrogen sulfide, which escapes to the inside wall at the pipe crown, is oxidized to sulfite molecules and sulfuric acid molecules under the action of sulfur bacteria [23]; sulfuric acid molecules then dissolve in the water droplets, due to temperature differences, producing sulfuric acid; consequently, the inside surface of the concrete pipe, which was originally alkaline, gradually becomes neutral and forms a bean curd-like watery gypsum layer under the long-term action of sulfuric acid. The chemistry of the corrosion process on the inside of pipe wall is:

$$
\begin{gathered}
\mathrm{SO}_{4}{ }^{2-}+\mathrm{C}+\mathrm{H}_{2} \mathrm{O} \rightarrow \mathrm{HCO}_{3}{ }^{-}+\mathrm{H}_{2} \mathrm{~S} \uparrow \\
2 \mathrm{H}_{2} \mathrm{~S}+\mathrm{O}_{2} \rightarrow \mathrm{SO}_{3}{ }^{2-} \rightarrow \mathrm{SO}_{4}{ }^{2-}+\mathrm{H}_{2} \mathrm{O} \rightarrow \mathrm{H}_{2} \mathrm{SO}_{4} \\
\mathrm{H}_{2} \mathrm{SO}_{4}+\mathrm{Ca}(\mathrm{OH})_{2} \rightarrow \mathrm{CaSO}_{4} \bullet 2 \mathrm{H}_{2} \mathrm{O} .
\end{gathered}
$$

The pipe physically deteriorates mostly at the crown. As the pipeline ages, the internal surface of the pipe roughens, the aggregate gradually becomes more exposed and the steel rebar in the pipe rusts. These actions decrease the load-bearing capacity of the pipeline and affect its normal operation. Figure 7 represents the pipe corrosion process. 


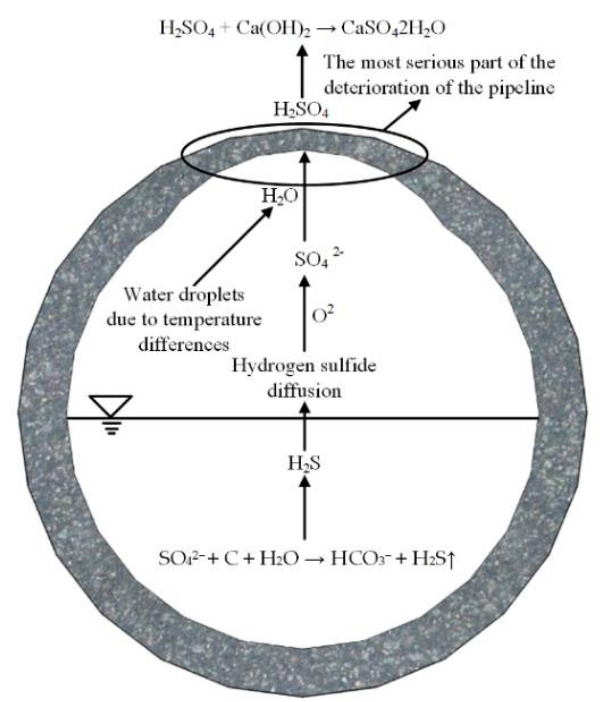

Figure 7. Pipe corrosion process.

\subsection{Model Description}

Compared with DEFORM software which is good at analyzing metal forming and LS-DYNA which is suitable for nonlinear dynamic analysis such as impact and contact [24-26]. ABAQUS is an advanced universal finite element system and one of the most powerful finite element software for analyzing complex solid mechanics and structural mechanics systems. Thus, a three-dimensional model of a buried corroded gasketed bell-spigot reinforced concrete drainage pipeline with two inspection chambers was developed using ABAQUS finite element software (Figure 8a). The length, width, and height of the model were 23,10 , and $8 \mathrm{~m}$, respectively. A sand bedding with thickness of $0.15 \mathrm{~m}$ was set at $120^{\circ}$ below the pipeline. An inspection chamber was placed at each end of the pipe. The length, width, and height of the inspection chambers were $2.5,2.5$, and $3.0 \mathrm{~m}$, respectively. The size of the pipe in the numerical simulation model is consistent with that in the full-scale test. The corrosion that reduced pipe wall thickness was simulated by excavating the pipe wall at the crown (Figure $8 \mathrm{~b}) ; d_{i}$ is the corrosion depth and $\alpha_{i}$ is the corrosion width, expressed as the cross-sectional angle at the springline subtended by the arc of the corrosion damage (in degrees).

A Mohr-Coulomb constitutive model was used for the soil and the sand bedding. The concrete damage plasticity constitutive model developed by Lee and Fenves [27] was used for the pipeline. The gasket, which was treated as a hyperelastic material in which stress and strain are not linearly related, was simulated by the Mooney-Rivlin strain energy function. The material parameters used in the model were consistent with the full-scale test and as shown in Table 1. The Mooney-Rivlin parameters are shown in Table 2.

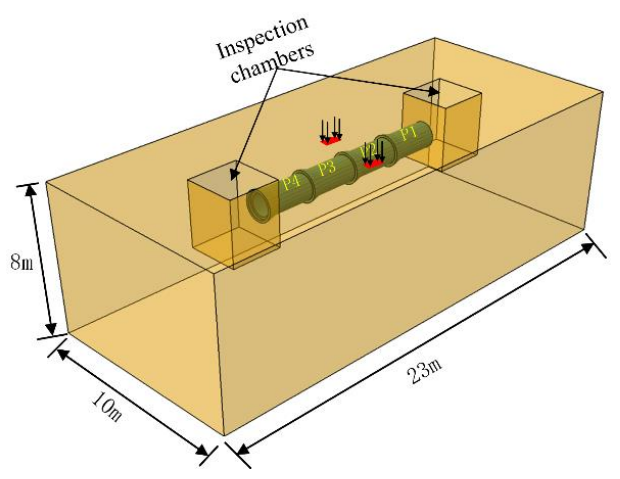

(a)

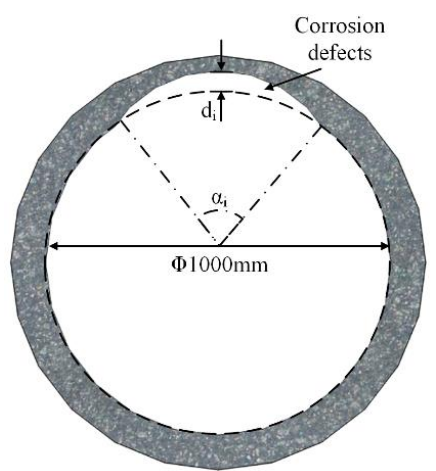

(b)

Figure 8. (a) The 3D model and (b) cross-section of pipe corrosion. 
Table 2. Parameters of Mooney-Rivlin strain energy function.

\begin{tabular}{ccc}
\hline$C_{\mathbf{1 0}}(\mathbf{P a})$ & $C_{\mathbf{0 1}}(\mathbf{P a})$ & $\left.D_{\mathbf{1}} \mathbf{P a}^{-\mathbf{1}}\right)$ \\
\hline 70,000 & 430,000 & $2.94 \times 10^{-5}$ \\
\hline
\end{tabular}

\subsection{Meshing the Pipeline Model}

It is critical for accurate mathematical simulation to control element quality and to choose an appropriate element type. Hypermesh 13.0 was used to mesh the pipeline model because the pipeline uses bell-and-spigot joints, and the mesh is extremely complicated. After the meshing was completed, the elements were exported into Abaqus for calculations. The minimum mesh size of the model was $0.02 \mathrm{~m}$, and the maximum size was $0.1 \mathrm{~m}$. These values take into account the results of the sensitivity analysis of the elements and the operational efficiency of the computer. Near-pipeline soil elements were densely meshed, and more distant elements were sparsely meshed. C3D8R (continuum, 3D, eight-node reduced-integration) elements were used to avoid shear locking, and the enhanced hourglass control formulation was used to avoid element distortion. The mesh geometry of the model is shown in Figure 9.

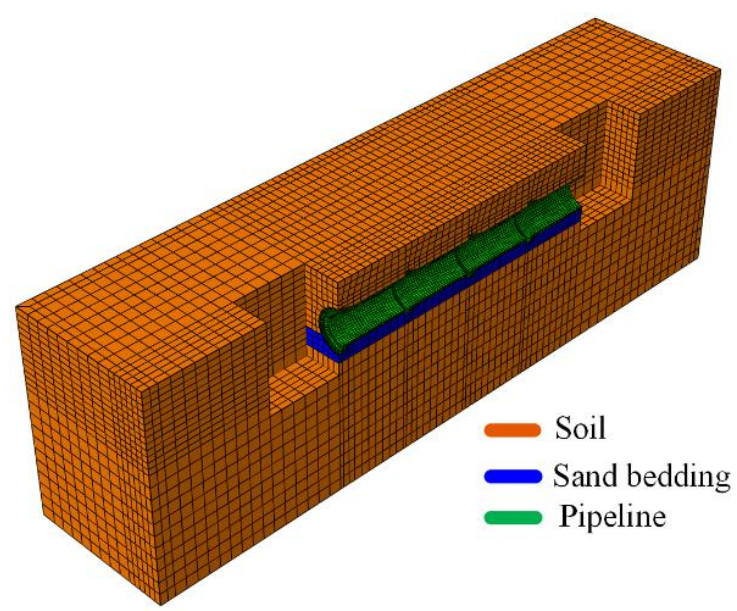

Figure 9. Mesh geometry of the pipeline model.

\subsection{Traffic Load Model}

Load on the ground due to traffic is the most frequent variable load acting on the pipe from above; it is a critical factor in the structural design of the pipeline. The code of structural design for special structures of water supply and wastewater engineering [28] allows the simplification of converting a dynamic traffic load to a static load by multiplication of a dynamic coefficient which is determined by the cover depth of the pipeline. Thus, we represented the traffic load, which acts on the pipe joints of P2 and P3, as a uniform static load. The dynamic coefficient is shown in Table 3.

Table 3. Dynamic coefficient.

\begin{tabular}{ccccccc}
\hline Cover Depth $(\mathbf{m})$ & $\mathbf{0 . 2 5}$ & $\mathbf{0 . 3 0}$ & $\mathbf{0 . 4 0}$ & $\mathbf{0 . 5 0}$ & $\mathbf{0 . 6 0}$ & $\geq \mathbf{0 . 7 0}$ \\
\hline Dynamic coefficient & 1.30 & 1.25 & 1.20 & 1.15 & 1.05 & 1.00 \\
\hline
\end{tabular}

\subsection{Model Interfaces}

Normal and tangential contact was set between the gasket and the pipe: the normal stiffness $K_{n}$ and the tangential shear modulus $K_{t}$ were set to $10,000 \mathrm{GPa} / \mathrm{m}$ and $8000 \mathrm{GPa} / \mathrm{m}$. Normal behavior for the pipe-soil interface was set to hard contact, and the tangential behavior was set to penalty. Liu [29] observed that the distribution of pipe-soil interaction is closely related to the relative stiffness of pipe 
and soil. Thus, we set different tangential friction coefficients at the pipe-soil interface because of the difference in relative stiffness between pipe-soil and pipe-bedding. The tangential friction coefficient $\mu$ was determined by Equation (2), according to Liu and Yang [30]:

$$
\mu=\tan \psi
$$

where $\psi$ is the friction angle.

\subsection{Boundary Conditions}

Two boundary conditions were set for the model:

(1) Apply a displacement constraint in the normal direction on the surrounding soil surface and the inspection chambers, and apply a displacement constraint in all directions on the bottom surface of the soil and the bases of the inspection chambers;

(2) Apply boundary conditions to the spigot of P1 and the bell of P4 to constrain the axial displacement and rotational freedom of the pipeline.

\section{Results and Discussion}

\subsection{Effect of Corrosion Depth on the Mechanical Characteristic of Pipeline}

In this section, corrosion width is $60^{\circ}$, cover depth is $1.0 \mathrm{~m}$, traffic load is $1.0 \mathrm{MPa}$, and corrosion is located at the crown. Different corrosion depths were simulated by chiseling out different thicknesses of the interior pipe wall. Corrosion depths of $0 \%, 30 \%$, and $60 \%$ were used to investigate the effect of corrosion depth on the mechanical properties of the pipeline.

Buco et al. [31] inspected an $1800 \mathrm{~km}$ sewer network and found that $26.7 \%$ of concrete pipe defects were related to joint displacements or openings. Therefore, we examined the mechanical properties of the pipe joint for different corrosion depths. Circumferential strains (the distribution of strain around the pipe circumference) on the inside and outside of the P2 bell and P3 spigot walls for different corrosion depths were calculated and the result was compared with the values obtained from the experiment (Figures 10 and 11). In the figure, SIM represents the model data and TEST represents the experimental data.

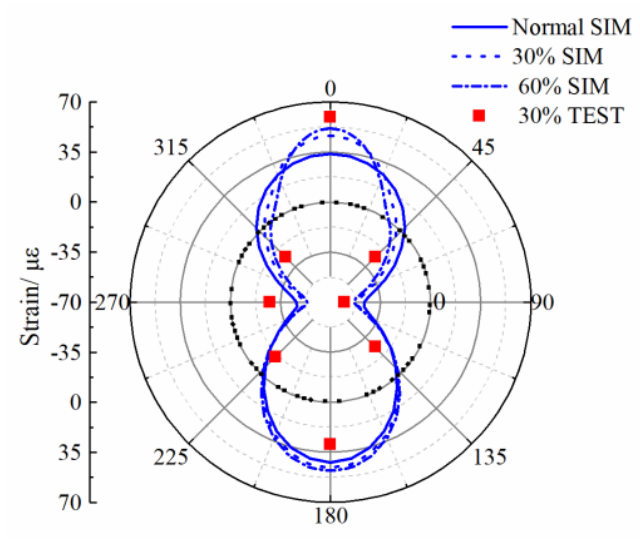

(a)

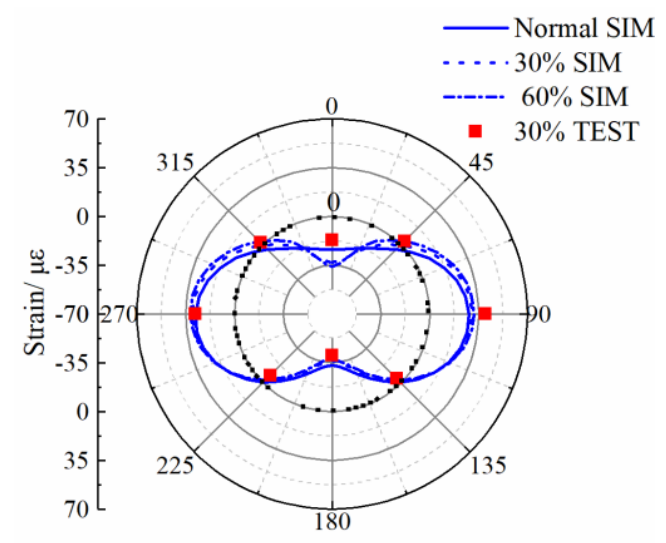

(b)

Figure 10. Circumferential strain curves of (a) outside (b) inside of the pipe bell wall at different corrosion depths. 


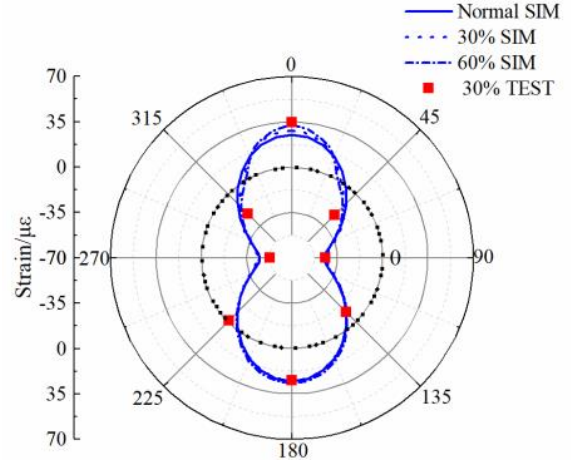

(a)

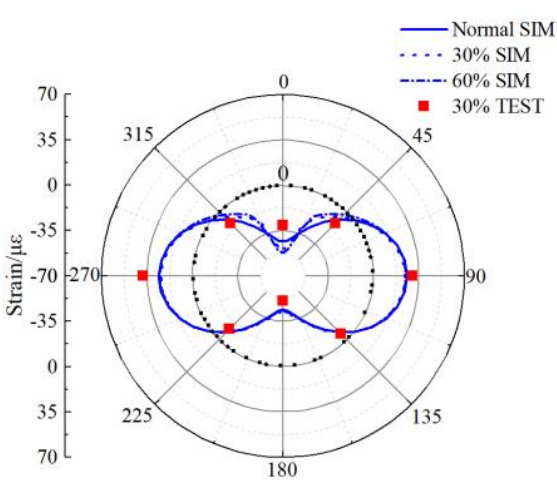

(b)

Figure 11. Circumferential strain curves of (a) outside (b) inside of the pipe spigot wall at different corrosion depths.

Figures 10 and 11 show that the model values and distributions of circumferential strains are consistent with the experimental results. The relative error is $<25 \%$ at the crown, the invert, and the springline, but the relative error at the $45-225^{\circ}$ and $135-315^{\circ}$ diameter regions of the pipe is relatively large, in the range $25 \%-40 \%$. The reasons for this difference are that the $45-225^{\circ}$ and $135-315^{\circ}$ diameter regions of the pipe are less stressed than other locations, the observed values at these positions are small, and the sensitivity to error is greater. Thus, the relative error at the $45-225^{\circ}$ and $135-315^{\circ}$ diameter regions of the pipe is correspondingly greater. The relative error was calculated using Equation (3):

$$
\delta=\Delta / L \times 100 \%
$$

where $\delta$ is the relative error, $\Delta$ is the difference between the numerical model results and the experimental data, and $L$ is the experimental data.

It can be seen from Figures 10 and 11 that circumferential strain on the inside and outside of the pipe wall increases as corrosion depth increases. The inside of the buried corroded pipe wall is in tension at the crown $\left(315-45^{\circ}\right)$ and the invert $\left(135-225^{\circ}\right)$ and is in compression at the springline $\left(45-135^{\circ}, 225-315^{\circ}\right)$, but for the outside pipe wall, the opposite is true. A comparison of Figures 10 and 11 shows that maximum circumferential strain of the pipe bell is much greater than that of pipe spigot. This is because the bell, which is convex, is more constrained by the soil than other parts of the pipe, but the spigot, which is inserted inside the bell, is not directly in contact with the soil and so the stress of the spigot is mainly transmitted through the gasket. Thus, the bell is more vulnerable to damage than the spigot. Comparing Figure 10a with Figure 10b, it can be seen that maximum circumferential strain of the inside of the pipe wall (at the crown) is much greater than that of the outside (at the springline), and the increase in the circumferential strain of the inside of the wall due to corrosion is much greater than that of the outside. This result indicates that the corroded area on the inside of the pipe wall is most susceptible to tensile damage, and the effect of corrosion depth on the inside is more significant than on the outside of the pipe wall.

Pipes are prone to crack under long-term operation, affecting the normal operation of the pipeline. To explore the relationship between the risk of the pipe cracking and corrosion depth, corrosion depths of $10 \%, 20 \%, 40 \%$, and $50 \%$ were calculated. The maximum principal stress in ABAQUS is the maximum value of the direct stress on the section in different directions at a point. Damage to the concrete, which has typical brittle characteristics, can be judged by the maximum principal stress and use of the four major criteria of material failure. It is assumed that the concrete pipe will crack along the longitudinal direction when the maximum principal stress is greater than the ultimate tensile strength of the concrete. Thus, the maximum values of the maximum principal stress at the crown, 
the springline, and the invert were determined to represent the relationship between the risk of the pipe cracking and corrosion depth (Figure 12).

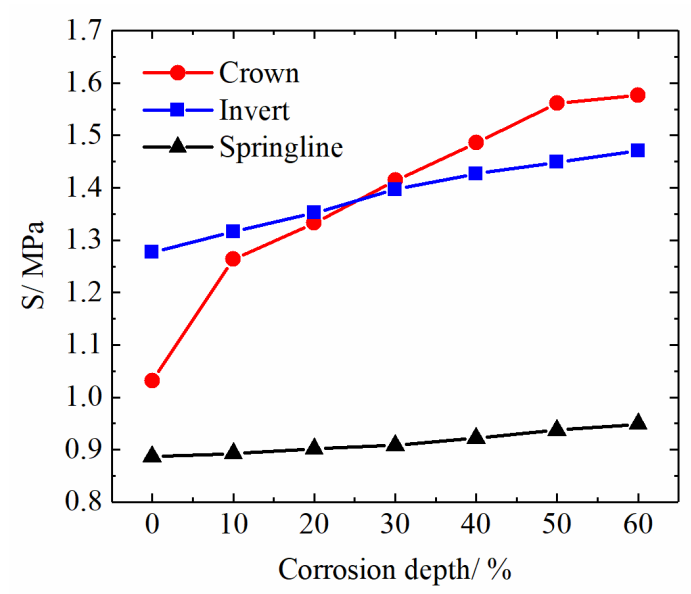

Figure 12. Relationships between the maximum principal stress and corrosion depth.

Figure 12 shows that the maximum principal stress at the crown, springline, and invert is positively correlated with corrosion depth. When the pipeline is not corroded, the maximum principal stress is greater at the invert than at the crown or the springline, which shows the least maximum principal stress. As corrosion depth increases, the maximum principal stress at the invert and springline increases slowly, but the maximum principal stress at the crown increases rapidly. When corrosion depth is $30 \%$, the maximum principal stress at the crown exceeds that at the invert, where it is assumed that no corrosion has occurred. These results show that the effect of corrosion on the pipe is extremely significant, especially in areas of corrosion in the pipe.

\subsection{Effect of Corrosion Width on the Mechanical Characteristic of Pipeline}

In this section, corrosion depth is $30 \%$, traffic load is $1.0 \mathrm{MPa}$, and cover depth is $1.0 \mathrm{~m}$. Different corrosion widths were set by altering the angle subtended by the arc of the corrosion width at the springline. Corrosion width values of $10^{\circ}, 60^{\circ}$, and $120^{\circ}$ were used in calculations to investigate the effect of corrosion width on the mechanical properties of the pipeline. As in Section 4.1, the circumferential path of P2 bell and P3 spigot were selected. The circumferential strain of the outside and inside of the pipe bell and pipe spigot walls for different corrosion widths are shown in Figures 13 and 14.

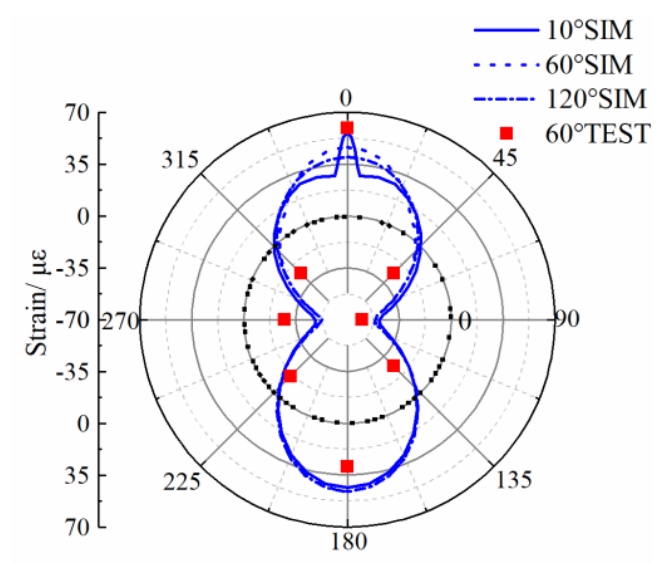

(a)

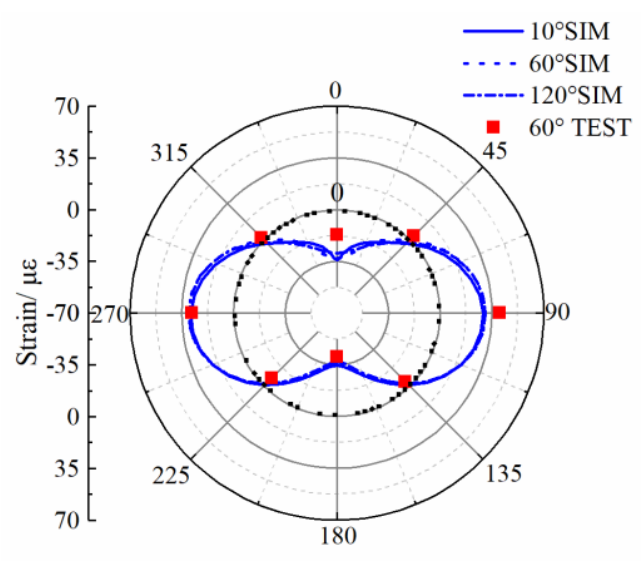

(b)

Figure 13. Circumferential strain curves of (a) inside and (b) outside of the pipe bell wall at different corrosion widths. 


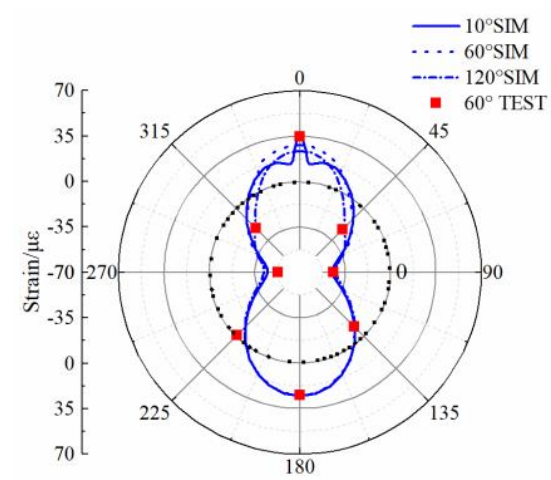

(a)

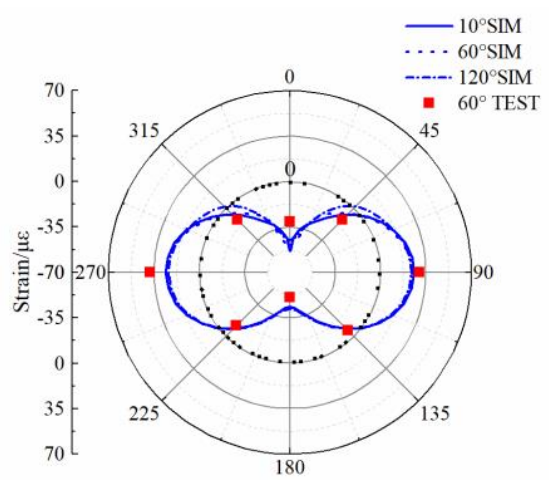

(b)

Figure 14. Circumferential strain curves of (a) inside and (b) outside of the pipe spigot wall at different corrosion widths.

Figures 13 and 14 show that the simulation results of the circumferential strains are consistent with the experimental results in distribution trends and values. Figures 13a and 14a show that circumferential strain on the inside changes abruptly in the corroded area at the crown and the value at which this change occurs decreases as corrosion width increases. This is mainly because when corrosion width is small, severe stress is concentrated at the corroded area of the pipe, which leads to a sharp increase in the maximum principal stress. As corrosion width increases, stress dissipates and the maximum principal stress in the area of corrosion correspondingly decreases. At some point, as corrosion width reaches a particular level, stress is not concentrated at any location and the effect of corrosion width on the maximum principal stress becomes extremely weak. Figures $13 \mathrm{~b}$ and $14 \mathrm{~b}$ show that circumferential strain on the outside of the pipe wall is almost coincident for different corrosion widths, which indicates that corrosion width has little effect on the outside of the pipe wall.

Because stress at the crown is very high when corrosion width is small and low when corrosion width is large, corrosion width values used in this section were densely clustered for smaller corrosion widths and were sparse for larger corrosion widths. To investigate the effect of corrosion width on pipe cracking, corrosion width values of $0^{\circ}, 20^{\circ}, 30^{\circ}, 45^{\circ}$, and $180^{\circ}$ were calculated. As in Section 4.1, the maximum values of the maximum principal stress at the crown, the springline and the invert under different corrosion width were extracted (Figure 15).

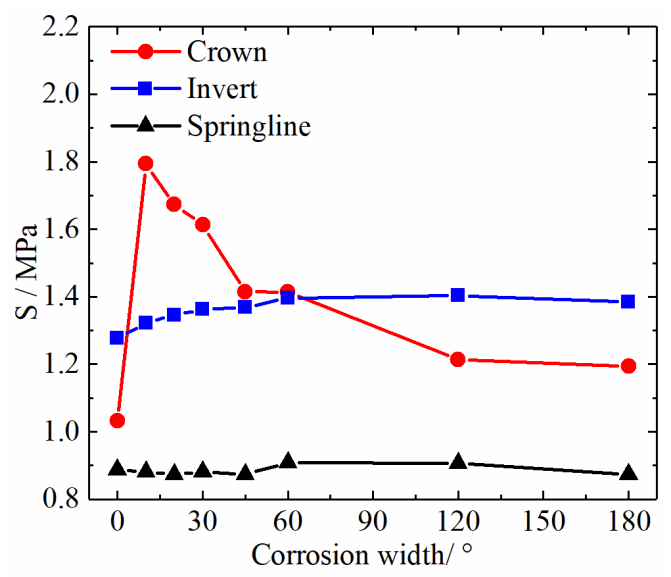

Figure 15. Relationship between the maximum principal stress of the pipe and corrosion width.

Figure 15 shows that as corrosion width increases, the maximum principal stress at the invert increases slowly, and the maximum principal stress at the springline does not change significantly. 
However, the maximum principal stress at the crown rapidly increases $\left(0-10^{\circ}\right)$, then rapidly decreases $\left(10-45^{\circ}\right)$, and lastly gradually decreases $\left(45-180^{\circ}\right)$. We infer that corrosion width has a great influence on the crown where there is corrosion, but has little effect on the springline or the invert, where there is no corrosion. This is consistent with the conclusions obtained from Figures 13 and 14 . There is a stress concentration that causes the strain at the corroded area to be greater than for other areas. This phenomenon becomes less pronounced as corrosion width increases.

In summary, the maximum principal stress of the pipe is negatively correlated with corrosion width. As corrosion width decreases, the probability of pipe failure increases. Therefore, when the pipe corrosion width is small, measures must be taken to prevent the rapid deterioration of the pipeline.

\subsection{Effect of Traffic Load on the Mechanical Characteristic of Pipeline}

In this section, corrosion depth is $30 \%$, corrosion width is $60^{\circ}$, and cover depth is $1.0 \mathrm{~m}$. The effects of traffic loads of $0.4 \mathrm{MPa}, 1.0 \mathrm{MPa}$, and 2.0 MPa were calculated. As in Section 4.1, the circumferential path of P2 bell and P3 spigot were selected. The circumferential strains of the outside and inside of the pipe bell and pipe spigot walls for different traffic loads are shown in Figures 16 and 17.

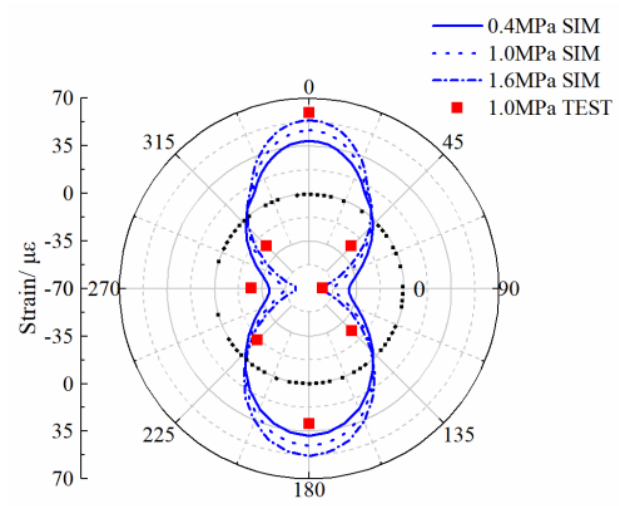

(a)

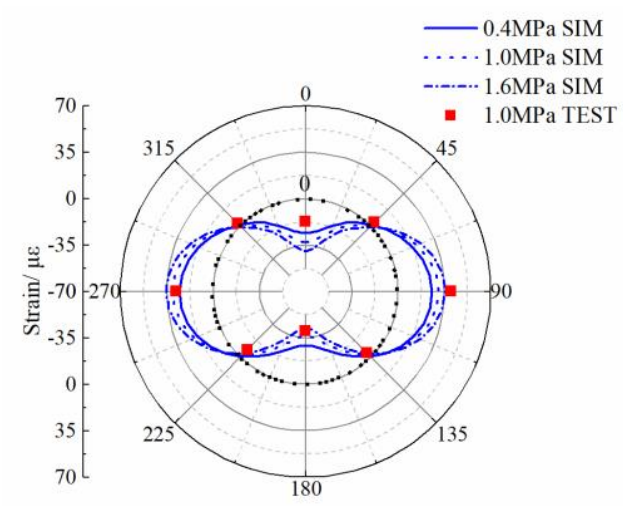

(b)

Figure 16. Circumferential strain curves of (a) outside (b) inside of the pipe bell wall for different traffic loads.

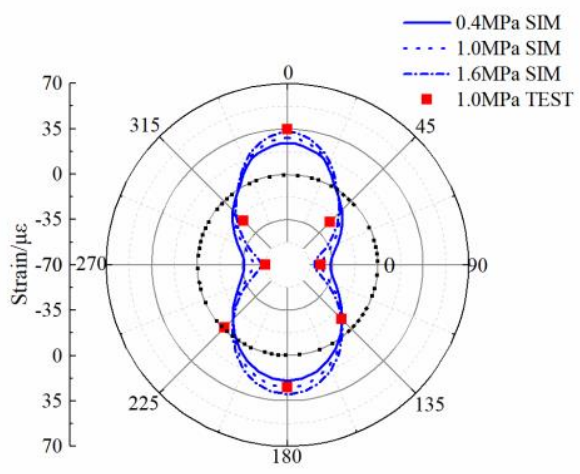

(a)

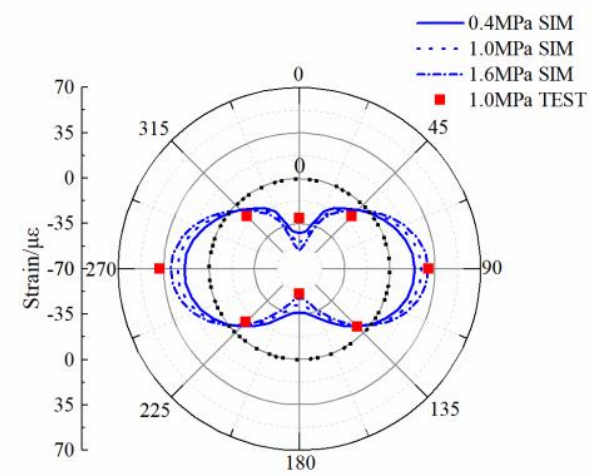

(b)

Figure 17. Circumferential strain curves of (a) outside (b) inside of the pipe spigot wall for different traffic loads.

Figures 16 and 17 show that the numerical simulation results are consistent with the full-scale test results. The circumferential strain of the inside and outside of the pipe wall under different traffic loads are coincident at the $45-225^{\circ}$ and $135-315^{\circ}$ diameter regions. However, circumferential strain at 
other pipe locations (crown, springline, and invert) increases as traffic load increases. We conclude that under traffic load, pipe deformation occurs mainly at the crown, invert, and springline, and that deformations at the $45-225^{\circ}$ and $135-315^{\circ}$ diameter regions of the pipe are extremely small.

Traffic load values of $0,0.2,0.6,0.8,1.2,1.4,1.8$, and $2.0 \mathrm{MPa}$ were calculated to investigate the effect of traffic load on pipe cracking. As in Section 4.1, the maximum values of the maximum principal stress at the crown, the springline and the invert under different traffic loads were extracted and analyzed (Figure 18).

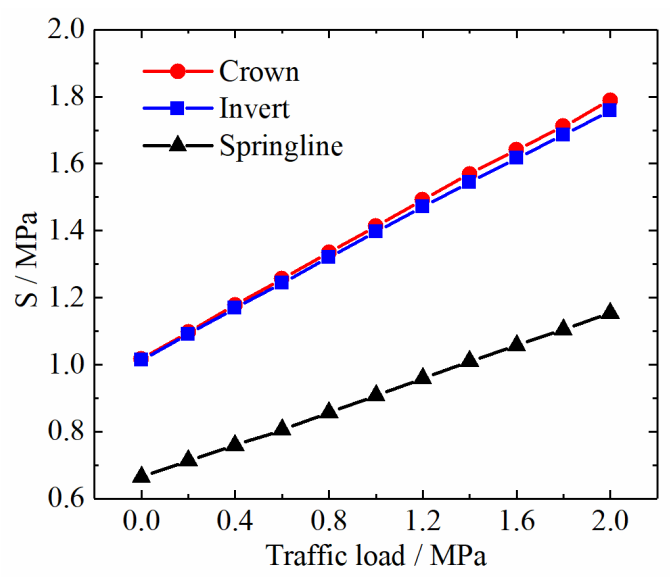

Figure 18. Relationships between the maximum principal stress and traffic load.

Figure 18 shows that the maximum principal stress at the crown, springline, and invert is positively linearly correlated with traffic load. When traffic load increases from 0 to $2.0 \mathrm{MPa}$, the maximum principal stress at the crown, springline, and invert increases by 1.76, 1.61, and 1.73 times. This result demonstrates that the influence of traffic load on the maximum principal stress is extremely significant. Therefore, for municipal engineering, control of vehicle load is related to the service life of a municipal road and to the operational safety of the municipal pipeline.

\subsection{Effect of Cover Depth on the Mechanical Characteristic of Pipeline}

In this section, corrosion depth is $30 \%$, corrosion width is $60^{\circ}$, and traffic load is $1.0 \mathrm{MPa}$. Cover depth values of 1.0, 2.0, and $3.0 \mathrm{~m}$ were calculated. As in Section 4.1, for calculation of the circumferential path of P2 bell and P3 spigot. The circumferential strain on the outside and inside of the pipe bell and pipe spigot walls for different cover depths are shown in Figures 19 and 20.

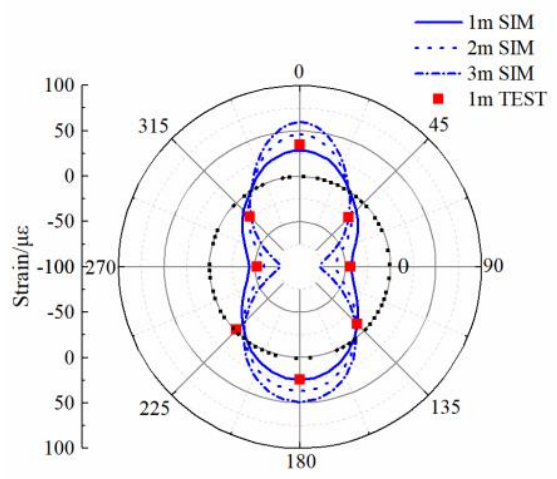

(a)

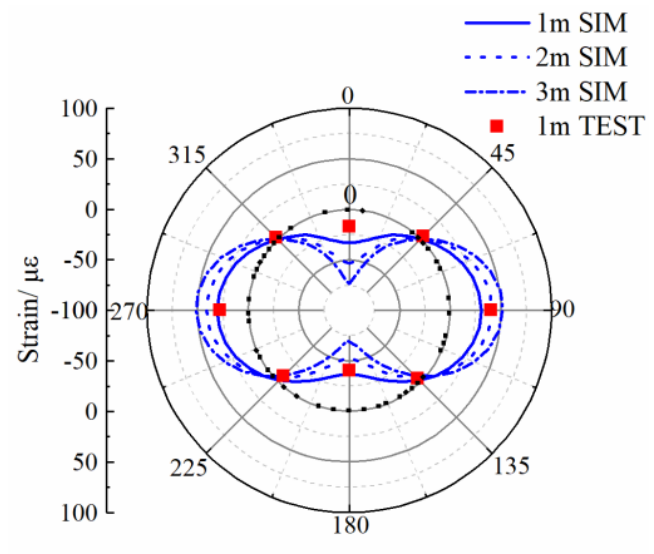

(b)

Figure 19. Circumferential strain curves of (a) outside and (b) inside of the pipe bell wall for different cover depths. 


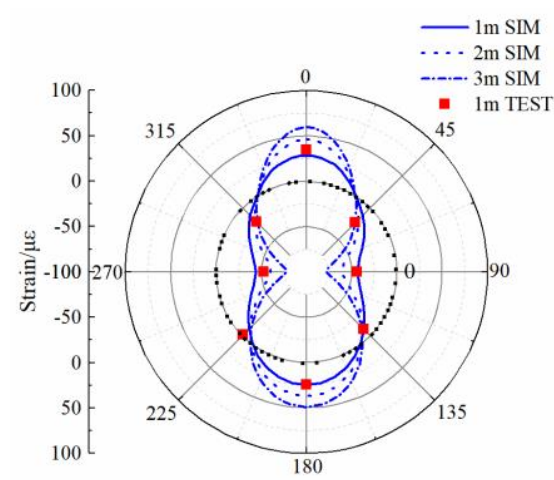

(a)

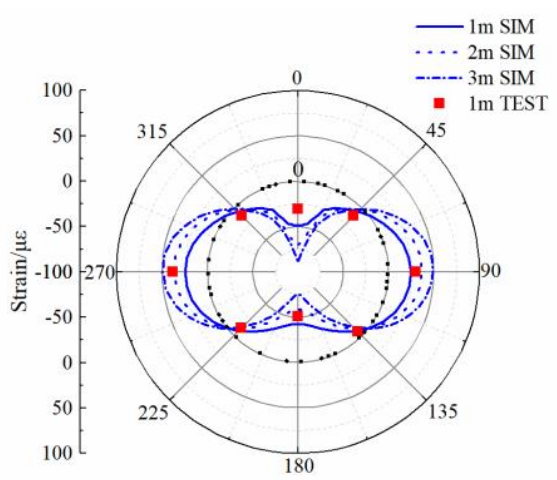

(b)

Figure 20. Circumferential strain curves of (a) outside and (b) inside of the pipe spigot wall for different cover depths.

Figures 19 and 20 show that the numerical simulation of the circumferential strain is consistent with that of the full-scale test. The circumferential strain of both the outside and inside of the pipe bell and pipe spigot walls increases as cover depth increases. The increase in circumferential strain on the outside of the wall is almost the same when cover depth increases from 1.0 to $2.0 \mathrm{~m}$ and from 2.0 to $3.0 \mathrm{~m}$. However, for the inside of the pipe wall, the increase in circumferential strain when cover depth increases from 1.0 to $2.0 \mathrm{~m}$ is significantly greater than when cover depth increases from 2.0 to $3.0 \mathrm{~m}$. This difference shows that the effect of cover depth on the inside of the wall is more significant than its effect on the outside.

Cover depth values of 1.5 and $2.5 \mathrm{~m}$ were calculated. As in Section 4.1, the maximum values of the maximum principal stress at the crown, the springline and the invert under different cover depth were extracted (Figure 21).

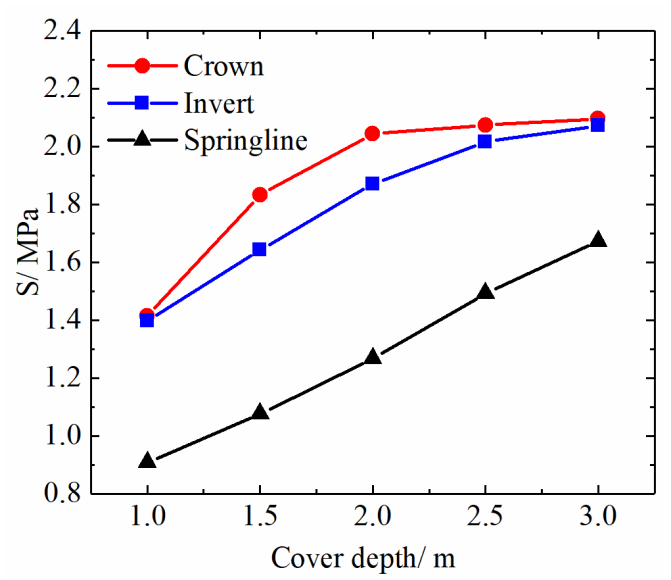

Figure 21. Relationship between the maximum principal stress and cover depth.

Figure 21 shows that the maximum principal stress at the springline is positively linearly correlated with cover depth. The maximum principal stress at the crown and invert is positively nonlinearly correlated with cover depth. The maximum principal stress at the crown and invert increases rapidly when cover depth increases from 1.0 to $2.0 \mathrm{~m}$, which is significantly greater than the increase in the maximum principal stress when cover depth increases from 2.0 to $3.0 \mathrm{~m}$. The main reason for this is that the effect of cover depth on pipe stress occurs in three steps. When cover depth is small, traffic load is important and stress is initially due to traffic load. When cover depth reaches a certain critical level, the effects of stress due to soil pressure and traffic load are equivalent. Finally, as cover depth continues 
to increase, the effects of soil pressure become greater, and stress is mainly due to soil pressure. Overall, soil dissipates traffic load. As cover depth increases, the effect of soil pressure on pipe stress increases gradually, but the effect of traffic load on pipe stress gradually decreases. Therefore, the rate of increase of the maximum principal stress in the pipe would decrease significantly as cover depth increases.

\section{Conclusions}

The effects of various factors on the mechanical properties of the pipe were investigated using a numerical model and a full-scale experiment. The main conclusions are as follows.

(1) The inside of the pipe wall is more vulnerable to damage than the outside. The inside of the pipe wall is in tension at the crown and invert and in compression at the springline. However, the opposite is true for the outside of the pipe wall.

(2) The stress and strain curves change abruptly in the area of pipe corrosion. Compared with the uncorroded pipeline, when the pipeline corrosion depth is 30\%, the stress and strain at pipe crown increased by about $50 \%$, and the stress and strain at pipe invert and pipe springline increased by about $10 \%$.

(3) When corrosion depth increased from $0 \%$ to $30 \%$, the stress and strain on inside of pipe crown increases by about $50 \%$, the stress and strain on inside of pipe crown increases by about $30 \%$. It shows that the effect of corrosion is more significant on the inside of the pipe wall than on the outside.

(4) The maximum principal stresses and circumferential strains of the pipe are positively correlated with the corrosion depth but negatively correlated with corrosion width. The stress and strain at the corroded area increase with increasing corrosion depth. With increasing of corrosion width, the stress and strain first increase rapidly $\left(0-10^{\circ}\right)$, then decreases rapidly $\left(10-45^{\circ}\right)$, and finally decreases slowly $\left(45-180^{\circ}\right)$.

(5) The greater cover depth or increasing traffic load causes a rapid increase in both circumferential strain and the maximum principal stress. It is recommended that pipes with a buried depth greater than $1.5 \mathrm{~m}$ and a traffic load greater than 1.0 MPa should be regularly inspected to detect pipeline damage.

Author Contributions: Conceptualization, H.F.; Data curation, F.W.; Formal analysis, P.T.; Funding acquisition, H.F.; Methodology, K.Y.; Project administration, B.L.; Supervision, X.D.; Writing-original draft, K.Y.; Writing-review \& editing, X.D.

Funding: This research was funded by the National Key Research and Development Program of China (No. 2016YFC0802400), the National Natural Science Foundation of China (No. 51678536), the Scientific and Technological Research Program of Henan Province (No. 152102310066), and the Outstanding Young Talent Research Fund of Zhengzhou University (1621323001), for which the authors are grateful.

Acknowledgments: The authors would like to thank the anonymous reviewers for their constructive suggestions to improve the quality of the paper.

Conflicts of Interest: The authors declare no conflict of interest.

\section{References}

1. An, G.F. Overview. In Technical Guide for Trenchless Rehabilitation Engineering of Urban Sewer Pipeline, 1st ed.; An, G.F., Ed.; China Architecture \& Building Press: Beijing, China, 2015; Volume 1, pp. 1-5.

2. Huang, D.; Liu, X.Y. Current state and future perspectives of sewer networks in urban China. Front. Environ. Sci. Eng. 2018, 12, 2-16. [CrossRef]

3. Hong, X.; Liu, Y. Nonlinear ultrasonic detection method for delamination damage of lined anti-corrosion pipes using PZT transducers. Appl. Sci. 2018, 8, 2240. [CrossRef]

4. Li, B. Numerical simulation and full—scale test on dynamic response of corroded concrete pipelines under Multi-field coupling. Constr. Build. Mater. 2019, 200, 368-386. [CrossRef]

5. Wang, F.M.; Fang, H.Y. Dynamic response analysis of drainage pipes with gasketed bell and spigot joints subjected to traffic loads. Chin. J. Geotech. Eng. 2018, 40, 2275-2280.

6. Lay, G.R.; Brachman, R.W. Full—scale physical testing of a buried reinforced concrete pipe under axle load. Can. Geotech. J. 2013, 51, 394-408. [CrossRef] 
7. Meesawasd, N.; Boonyasiriwat, C. Finite element modeling for stress analysis of a buried pipeline under soil and traffic loads. In Proceedings of the 2016 IEEE International Conference on Industrial Engineering and Engineering Management (IEEM), Bali, Indonesia, 4-7 December 2016; pp. 385-390.

8. Rakitin, B.; Xu, M. Centrifuge testing to simulate buried reinforced concrete pipe joints subjected to traffic loading. Can. Geotech. J. 2015, 52, 1762-1774. [CrossRef]

9. Xu, M.; Shen, D.; Rakitin, B. The longitudinal response of buried large-diameter reinforced concrete pipeline with gasketed bell—and—spigot joints subjected to traffic loading. Tunn. Undergr. Space Technol. 2017, 64, 117-132. [CrossRef]

10. Dong, F.F. Experimental and Numerical Study on the Strain Behavior of Buried Pipelines Subjected to an Impact Load. Appl. Sci. 2019, 9, 3284. [CrossRef]

11. Buco, J.; Fabrice, E. Full-scale experimental determination of concrete pipe joint behavior and its modeling. J. Infrastruct. Syst. 2008, 14, 230-240. [CrossRef]

12. Fang, H.; Li, B. The mechanical behaviour of drainage pipeline under traffic load before and after polymer grouting trenchless repairing. Tunn. Undergr. Space Technol. 2018, 74, 185-194. [CrossRef]

13. Motta, R.S. Comparative studies for failure pressure prediction of corroded pipelines. Eng. Fail. Anal. 2017, 81, 178-192. [CrossRef]

14. $\mathrm{Xu}, \mathrm{W}$. Corroded pipeline failure analysis using artificial neural network scheme. Adv. Eng. Softw. 2017, 112, 255-266. [CrossRef]

15. Han, C.J.; Zhang, H. Failure Pressure Analysis of the Pipe with Inner Corrosion Defects by FEM. Int. J. Electrochem. Sci. 2016, 11, 5046-5062. [CrossRef]

16. Ye, H.; Yan, S.T. Collapse of Corroded Pipelines under Combined Tension and External Pressure. PLoS ONE 2016, 11, 1-7. [CrossRef]

17. Zhou, W.X. Reliability evaluation of corroding pipelines considering multiple failure modes and time-dependent internal pressure. J. Infrastruct. Syst. 2011, 17, 216-224. [CrossRef]

18. Huang, Q.; Miran, S.A. Time-dependent reliability analysis of corroded buried pipelines considering external defects. J. Infrastruct. Syst. 2016, 22, 04016019.

19. Ahammed, M.; Melchers, R.E. Probabilistic analysis of underground pipelines subject to combined stresses and corrosion. Eng. Struct. 1997, 19, 988-994. [CrossRef]

20. Ministry of Housing and Urban-Rural Development of the People's Republic of China. GB 50268-2008 Code for Construction and Acceptance of Water and Sewerage Pipeline Works[S]; China Architecture \& Building Press: Beijing, China, 2009.

21. General Administration of Quality Supervision. Inspection and Quarantine of the People's Republic of China. GB/T 11836-2009 Concrete and Reinforced Concrete Sewer Pipes; Standards Press of China: Beijing, China, 2009.

22. Erickson, L.E. The control of sulphides in sewerage systems. Aiche J. 1973, 19, 880. [CrossRef]

23. Zhou, Z.; Cai, X.; Ma, D.; Du, X. Water saturation effects on dynamic fracture behavior of sandstone. Int. J. Rock Mech. Min. Sci. 2019, 114, 46-61. [CrossRef]

24. Liu, F.; Feng, W.; Xiong, Z. Impact performance of new prestressed high-performance concrete pipe piles manufactured with an environmentally friendly technique. J. Clean. Prod. 2019, 231, 683-697. [CrossRef]

25. Erdakov, I.N. Computerized study of intense deformed state of grinding plate of high-manganese steel. Solid State Phenom. 2018, 284, 563-567. [CrossRef]

26. Erdakov, I.N.; Ivanov, V.A.; Pashnyov, V.A. Studies of highly filled composite based on two-component organic binder stress state in thermal Stress. Procedia Manuf. 2018, 22, 325-330. [CrossRef]

27. Lee, J.; Fenves, G.L. Plastic-damage model for cyclic loading of cement structures. J. Eng. Mech. 1998, 124, 892-900. [CrossRef]

28. Ministry of Construction of the People's Republic of China. GB 50332-2002 Structural Design Code for Special Structures of Water Supply and Waste Water Engineering; China Architecture \& Building Press: Beijing, China, 2002.

29. Liu, Q.L. Calculating method and analysis of plane strain question of interaction between buried pipe and soil. Rock Soil Mech. 2007, 28, 83-88. 
30. Liu, Q.L.; Yang, M. Analytical model and parameters determination of interaction between buried pipe and soil. Rock Soll Mech. 2004, 25, 728-731.

31. Buco, J.; Emeriault, F.; Le Gauffre, P.; Kastner, R. Statistical and 3D numerical identification of pipe and bedding characteristics responsible for longitudinal behavior of buried pipe. In Pipelines 2006: Service to the Owner; ASCE: Reston, VA, USA, 2006; pp. 1-10. 